\title{
Bio-Fertilization Effect on the Productivity and Biodiesel Quality of Castor Plant Oil under El-Salam Canal Irrigation Condition
}

\author{
Reham K. Badawy ${ }^{1}$, Amal M. Omer ${ }^{2}$ and Doaa I. Othman ${ }^{3}$
}

\begin{abstract}
El-Salam canal as a marginal water can be utilized for the irrigation of non-traditional plants such as castor oil plant for biodiesel production. The article aim to maximize yield and oil content of castor plants for production of biodiesel using either biofertilizers or plant growth hormones. Two bacterial strains (Azotobacter chrococcum and Pseudomonas geniculata) of high potential to produce indole acetic acid (IAA) and indole-3-butyric acid (IBA) and two synthetic growth hormones (IAA or IBA) were used.
\end{abstract}

A field experiment, conducted at Baloza Experimental Station, North Sinai which irrigated with El-Salam water, revealed that application of growth hormones (IAA and IBA) or biofertilizer (Azotobacter chrococcum or Pseudomonas geniculata) separately or as mixture had positive effect on all growth parameters of castor plants, nitrogen and phosphorus uptake and total microbial populations in their rhizosphere. The IBA and Azotobacter chrococcum followed by Pseudomonas geniculata recorded the highest plant length, inflorescence weight, plant dry weight, weight of 1000 seeds and oil content.

The results revealed that the treated plants with foliar application or biofertilizer separately increased the contents of trace and heavy metals in shoot plants, the combined treatments recorded the highest significant values for most elements studied. At the same time, usage of IAA and IBA mixture and A.chrococcum showed a significant superiority of available heavy metal contents in the soil.

It was observed that the viscosity of all castor oil samples at $25^{\circ} \mathrm{C}$ was extremely higher than that of petroleum diesel, no remarkable variations in the viscosity of castor oil samples was recorded among treated or untreated castor plants. As esterification of three selected castor oil samples was performed, their viscosity reduced and so, biodiesel was produced. Characterization of three biodiesel samples revealed that only flash and cloud point conformed to the standard ranges, while viscosity, carbon residue and heat resistance exceeded the standards of biodiesel. It is recommended to blend the biodiesel obtained with other diesel to minimize the viscosity of fuel.

Keyword: El-Salam irrigation water, Castor plant, Biodiesel, Biofertilizer, Azotobacter chrococcum, , Pseudomonas geniculata, Foliar application, Heavy metals.

\footnotetext{
${ }^{1}$ Environmental Pollution Unit, Department of Plant Ecology and Range Management, Desert Research Center (DRC), Cairo, Egypt. ${ }^{2}$ Soil Microbiology Department., Desert Research Center (DRC), Egypt. ${ }^{3}$ Petroleum Research Center

Received March 05, 2018, Accepted March 31, 2018
}

\section{INTRODUCTION}

El Salam Canal Project was implemented as a national project to divert efficient amount of drainage water to nearly reclaimed area after blending with the Nile water. It transported a mixture of drainage water from Hadous and El-Serw drains together with the fresh water from the Damietta branch in equal volumes of fresh and drainage water (Balba, 1997). Most of waste waters are dumped straight into rivers, lakes and estuaries without any treatment (Yehia and Sabae, 2011). The canal water is generally acceptable for irrigation, but with some worries and precautions about the reverse effect of wastewater use in the irrigation of edible crops (Toze, 2005). Long-term application of treated and untreated wastewater resulted in significant buildup of heavy metals in soil (Khan et al., 2008). For this, cultivation of nontraditional plants for different purpose other than feeding is recommended. One of these is the production of biofuel or biodiesel which is a clean burning, renewable, non-toxic, biodegradable and environment friendly fuel (Ingle and Nandedkar,2010). Biodiesel fuel refers to any diesel-equivalent biofuel made from renewable biological materials as vegetable oils or animal fats. The term biodiesel usually refers to an ester made from the oil and methanol or applied to any trans esterified vegetable oil that makes it suitable for use as a diesel fuel. Different vegetable oils could be used for biodiesel production as soybean, coconut, sunflower, groundnut, castor oil ,etc ( Agrawal et $a l ., 2008)$.

Castor (Ricinus communis L.) that belongs to the Euphorbiaceae family is one of the most promising nonedible oil crops, due to its high annual seed production and yield, and since it can be grown on marginal land and in semi-arid climate. Beside using its oil for biofuel production, it is a raw material for a number of industrial chemicals like surfactants, greases and lubricants, specialty soaps, surface coatings, cosmetics and personal care products, pharmaceuticals, biodiesel, etc. Biodiesel obtained from castor oil has a lower cost compared to that obtained from other oils due to its solvability in alcohol without heating during transesterification and it also satisfies the relevant quality standards (Conceicao et al.,2007). 
Bio-fertilizers have a great importance in agriculture sector for their potential role in food safety and sustainable crop production by improving soil fertility and crop productivity plant. The beneficial effects of bio-fertilizer in improving plant growth are through the supply of fixed nitrogen and the production of phytohormones (Elmerich,1984). Soil bacteria modulate plant hormone status by releasing exogenous hormones and metabolites (Egamberdieva , 2009). While indole-3-acetic acid (IAA) is the most abundant naturally occurring auxin, (IBA) is also considered as an active auxin. Accumulation of IAA in plants affect cell elongation, root and shoot growth as it is necessary for developing and maturity of leaves and formation of lateral primordia in both root and shoot apical meristems (Salisbury and Ross,1992). Furthermore, auxin IBA is very effective in the promotion of adventitious root formation, as demonstrated in apple plants (Alvarez et al., 1989).

The aims of this research were: (1) Production of biodiesel apart from traditional agricultural crops, like castor plants (non-edible oil plant), that act as a better economical alternative. (2) Maximizing the usage of marginal water to produce biodiesel from castor plants under El-Salam canal irrigation conditions. (3) Maximizing castor oil yield using either synthetic or natural (Bacterial) plant growth hormones as IAA and IBA.

\section{MATERIALS AND METHODS}

\section{Evaluation of rhizobacteria as IAA and IBA producers}

Ten rhizobacterial strains of genera Azotobacter and Pseudomonas as, highly efficient plant growth promoting bacteria (PGPB), were assayed for their production of IAA and IBA hormones using HPLC assay. Bacterial isolates were grown for 48hours on their specific media supplemented with tryptophane at 1 $\mathrm{gm} / \mathrm{L}$. Bacterial supernatants were collected , acidified to $\mathrm{pH} 2.5$ to 3.0 with $1 \mathrm{~N} \mathrm{HCl}$ and extracted twice with ethyl acetate at double the volume of the supernatant. Extracted ethyl acetate fraction was evaporated to dryness in a rotatory evaporator at $40^{\circ} \mathrm{C}$. The extract was dissolved in $3 \mathrm{ml}$ of methanol and kept at $-20^{\circ} \mathrm{C}$. Samples of microbial Hormone were analyzed by High Performance Liquid Chromatography using HPLC Ultimate 3000 Thermo dionex. Retention times for peaks were compared to those of authentic standards added to the medium and extracted by the same procedures used with bacterial cultures. Quantification was done by comparison of peak heights (Hanifi and El Hadramy, 2008).

\section{Field Experiment}

A field experiment was conducted at Baloza Experimental Station, North Sinai, Egypt, location (N $31^{0} 1^{-} 43.0296^{--}$, E $\left.32^{0} 35^{-} 28.0431^{--}\right)$during 2016 and 2017 growing seasons to study the effect of both plant growth promoting bacteria and plant growth hormones on the productivity of castor plants (Ricinus communis) as well as characters of its oil and biodiesel. Castor seeds of Araishy variety obtained from Agricultural Research Centre were used. The experiment was designed in a split -plot design with 12 combinations involving four foliar spray treatments of $100 \mathrm{ppm}$ Indole acidic acid (IAA) or Indole butaric acid (IBA) separately, mixture of IAA: IBA by 1:1 and without as control) and three bio-fertilizers types (Azotobacter chrococcum, Pseudomonas geniculata and without as control) with four replicates .Bio-fertilizer was applied as seed inoculation and soil drench after one month of planting. Foliar application was carried out twice after 30 and 60 days from sowing. Phosphatic fertilizer as calcium super phosphate $\left(15.5 \% \mathrm{P}_{2} \mathrm{O}_{5}\right)$ was added at a rate of $150 \mathrm{~kg} /$ fed. during seed bed preparation, $100 \mathrm{Kg}$ of potassium sulphate $\left(50.0 \% \quad \mathrm{~K}_{2} \mathrm{SO}_{4}\right)$ was added at flowering stage, whereas nitrogen fertilizer was applied as ammonium sulfate $(20.5 \% \mathrm{~N})$ at rate of $250 \mathrm{~kg} / \mathrm{fed}$. (half of recommended dose), where $1 / 3$ of the amount was incorporated in dry soil before sowing, 1/3 was added one month after sowing and the rest was added one week pre-flowering stage.

\section{Soil and irrigation water analysis}

Initial soil samples (before any treatment or fertilization) were collected at $0-30 \mathrm{~cm}$ depth and their physiochemical properties were determined. At the end of field experiment, soil samples were collected at the top $30 \mathrm{~cm}$ in each treatment, air-dried, sieved to $2 \mathrm{~mm}$ and reserved for analysis. For initial soil, physiochemical properties as $\mathrm{pH}$, electrical conductivity (EC), cationic and anionic compositions were determined according to the methods described by Richards (1954) and Jackson (1963), while particle size distribution by the pipette method of Piper (1950). In addition, total content of the studied elements in the filtered extracts obtained from samples digested by conc. $\mathrm{HNO}_{3}+$ conc. $\mathrm{H}_{2} \mathrm{SO}_{4}+60 \% \mathrm{HCLO}_{4}$ were analysed as outlined by Hesse (1971). At harvest, all soil samples extracted using DTPA (Diethylene Triamine Pentaacetic Acid) were analysed for these elements availability according to Lindsay and Norvell (1978).

For water sample, $\mathrm{pH}$, total salinity (EC), major cations $\left(\mathrm{Na}^{+}, \mathrm{K}^{+}, \mathrm{Mg}^{2+}, \mathrm{Ca}^{2+}\right)$ and major anions $\left(\mathrm{Cl}^{-}\right.$, $\mathrm{SO}_{4}{ }^{2-}, \mathrm{CO}_{3}{ }^{2-}, \mathrm{HCO}_{3}{ }^{-}$) were determined by ion chromatography (ICS-1100, Dionex, Sunnyvale, CA, 
USA). Heavy metals and trace elements as $\mathrm{Al}, \mathrm{Cd}, \mathrm{Ni}$, $\mathrm{Pb}, \mathrm{Cr}, \mathrm{Cu}, \mathrm{Fe}, \mathrm{Mn}, \mathrm{Zn}, \mathrm{Co}$ and $\mathrm{Mo}$ for water and soil were analysed using Inductively Coupled Argon Plasma, iCAP 6500 Duo, Thermo Scientific, England. $1000 \mathrm{mg} / \mathrm{l}$ multi-element certified standard solution, Merck, Germany was used as stock solution for instrument standardization. For microbiological analysis of water, fecal coliform number were determined using MacConkey medium at $44^{\circ} \mathrm{C}$ for $24 \mathrm{hr}$ (APHA, 1998).

\section{Plant sampling and analysis}

After harvest, five castor plants were collected from each treatment with four replicates to determine some growth parameter as: plant height $(\mathrm{cm})$, number of branches/plant, number of inflorescences/plant, inflorescence length $(\mathrm{cm})$, plant dry weight (Kg/feddan), inflorescence weight (g/plant), inflorescence yield (kg/feddan) and 1000-seed weight (g). Shoot samples were dried at $60^{\circ} \mathrm{C}$, grounded and plant powder $(0.5 \mathrm{~g})$ was digested according to Norvell (1984) using a mixture of $\mathrm{H}_{2} \mathrm{SO}_{4}, \mathrm{HNO}_{3}$ and $\mathrm{HClO}_{4}$ for analysis of essential heavy metals and trace elements. Other plant samples were digested with $\mathrm{H}_{2} \mathrm{O}_{2}$ and $\mathrm{H}_{2} \mathrm{SO}_{4}$ by Nicholson (1984) and then subjected to analysis of nitrogen and phosphorus according to modified Micro-Kjeldahl method described by Peach and Tracey (1956) and method described by Rowell (1993),respectively, then total $\mathrm{N}$ or $\mathrm{P}$ uptake were calculated separately according to Sharma and Dadhwal (1996) by the following formula:

$$
=\frac{\text { N\%orP\% Xdry matter }(\mathrm{kg} / \text { feddan })}{100}
$$

Heavy metals and trace elements as $\mathrm{Al}, \mathrm{Cd}, \mathrm{Ni}, \mathrm{Pb}$, $\mathrm{Cr}, \mathrm{Cu}, \mathrm{Fe}, \mathrm{Mn}, \mathrm{Zn}, \mathrm{Co}$ and Mo for plant samples were analysed as that for water and soil. Seed oil content was determined using Soxhlet apparatus and petroleum ether $\left(40-60^{\circ} \mathrm{C}\right)$ as solvent, then oil \% was calculated according to (A.O.A.C,1990).

\section{Microbiological analysis of castor rhizosphere}

Total bacteria, Azotobacter and Pseudomonas counts in the rhizosphere were estimated at harvest by standard microbiological techniques using Nutrient medium, Ashby's and King media, respectively. Soil dehydrogenase activity ( $\mu \mathrm{g} \mathrm{TPF} / \mathrm{g}$ dry soil/24 hr.) was analyzed by the reduction of 2,3,5-triphenyl tetrazolium chloride (TTC) to triphenyl formazan (TPF) as described by Pepper et al. (1995).

\section{Oil viscosity}

Viscosity of all oil samples were determined @ 25 ${ }^{\circ} \mathrm{C}$ by Stabinger Viscometer SVM 3000 according to the ASTM D-445 and three crude oil samples were selected for production of biodiesel.

\section{Biodiesel production and characterization}

To improve the viscosity of oil for fuel production, oil samples were esterified and biodiesel produced. For biodiesel production, selected crude oil samples were esterified with low molecular weight alcohols as described by Sreenivas et al. (2011). Briefly, for one liter of castor oil, 300-330 ml of methanol and $10 \mathrm{ml}$ of concentrated sulfuric acid was added, the mixture was stirred continuously for about 6 hours at $65-70^{\circ} \mathrm{C}$. The mixture was allowed to settle for 8 hours until two separate layers were observed. The upper layer was methyl ester (Biodiesel) and the lower one was a mixture of crude glycerin, soap and residual methanol. The obtained biodiesel was taken in a separating funnel, washed with hot water at 40 ? C, shaken well and allowed to settle to separate two layers for nearly 7-8 hours. Above process is repeated at least three times so that the traces of glycerin and soap get removed and the biodiesel produced from castor oil is ready for use.

Characterization of castor biodiesel obtained from selected oil samples were conducted, that different properties as viscosity, flash point, cloud point, density and specific heat were tested according to ASTM D 6751 standard.

\section{Statistical analysis}

The split plot design with four replicates was used, where the main plots devoted to foliar application of IAA, IBA, IAA+TBA and control, while the Sub-plots were occupied by biofertilizers (Azotobacter chrococcum, Pseudomonas geniculata and control). Data obtained from plant and soil analysis were subjected by MSTAT-C (Freed, 1991). Means were compared using LSD test. Pearson's Product-Moment correlation analysis between chemical properties of castor plant measurement_and availability of heavy and trace element of soil were carried using SPSS program.

\section{RESULTS AND DISCUSSION}

\section{Growth regulators produced by $A$. chrococcum and Ps. geniculata}

Assay of growth regulators (IAA and IBA) in ten plant growth promoting bacteria using HPLC revealed that all Azotobacter and Pseudomonas isolates could produce IAA in their growing media with different quantities ranged from (49.6 to $216.8 \mathrm{ppm}$ ). Indole-3-acetic acid (IAA) is the most abundant naturally occurring auxin in plant and bacteria (Egamberdieva, 2009). On contrary, all isolates of Pseudomonas and only two of Azotobacter could secret the IBA in the quantitities ranged from (97.8 to $157.1 \mathrm{ppm})$. Auxin is quantitatively the most abundant phytohormones secreted by plant associated rhizobacteria, among auxin-like compounds, there exist indole-3-propionic 
acid (IPA),indole butyric acid and naphthalen acetic acid, (Lin and $\mathrm{Xu}, 2013)$. As in Table (1) and Figure (1), two bacterial strains (Azotobacter chrococcum and Pseudomonas geniculata) which secreted the highest IAA and IBA were selected for field experiment.

\section{Physical and chemical properties of the initial} experimental soil

The experimental pre-sowing soil was classified under the sand textural class, which has a considerable amount of sand $(91.12 \%)$ as indicated in Table (2). The results revealed that calcium carbonate content of the soil was low (1\%), pH was found to be slightly alkaline (7.9) which is desirable in agricultural soil, and the electrical conductivity was (EC,1080 $\mu \mathrm{mmohs} / \mathrm{cm})$. This noticeable increase in EC may result from irrigation with high EC of El-Salam Canal (2800 $\mu \mathrm{mmohs} / \mathrm{cm})$. This increase in EC values surely reflected the increase of cations and anions of $\mathrm{Ca}^{++}$, $\mathrm{Mg}^{++}$and $\mathrm{SO}_{4}{ }^{=}$. At surface depth $(0-30 \mathrm{~cm})$, there were high concentrations of total heavy metals and trace elements with regard to Goma, (2007) as controls with limitation in available values of most metals as shown in Table (2), all metals concentrations were lower than the standard limits except $\mathrm{Ni}$ which was $186.19 \mathrm{ppm}$ compared to $4.34 \mathrm{ppm}$ as standard (Goma, (2007)), in addition to high value of $\mathrm{Cr}$ which was $161.38 \mathrm{ppm}$, the directive of the Minister of Environment states that the

Table1.Growth regulators produced by $A$. chrococcum and Ps. geniculata

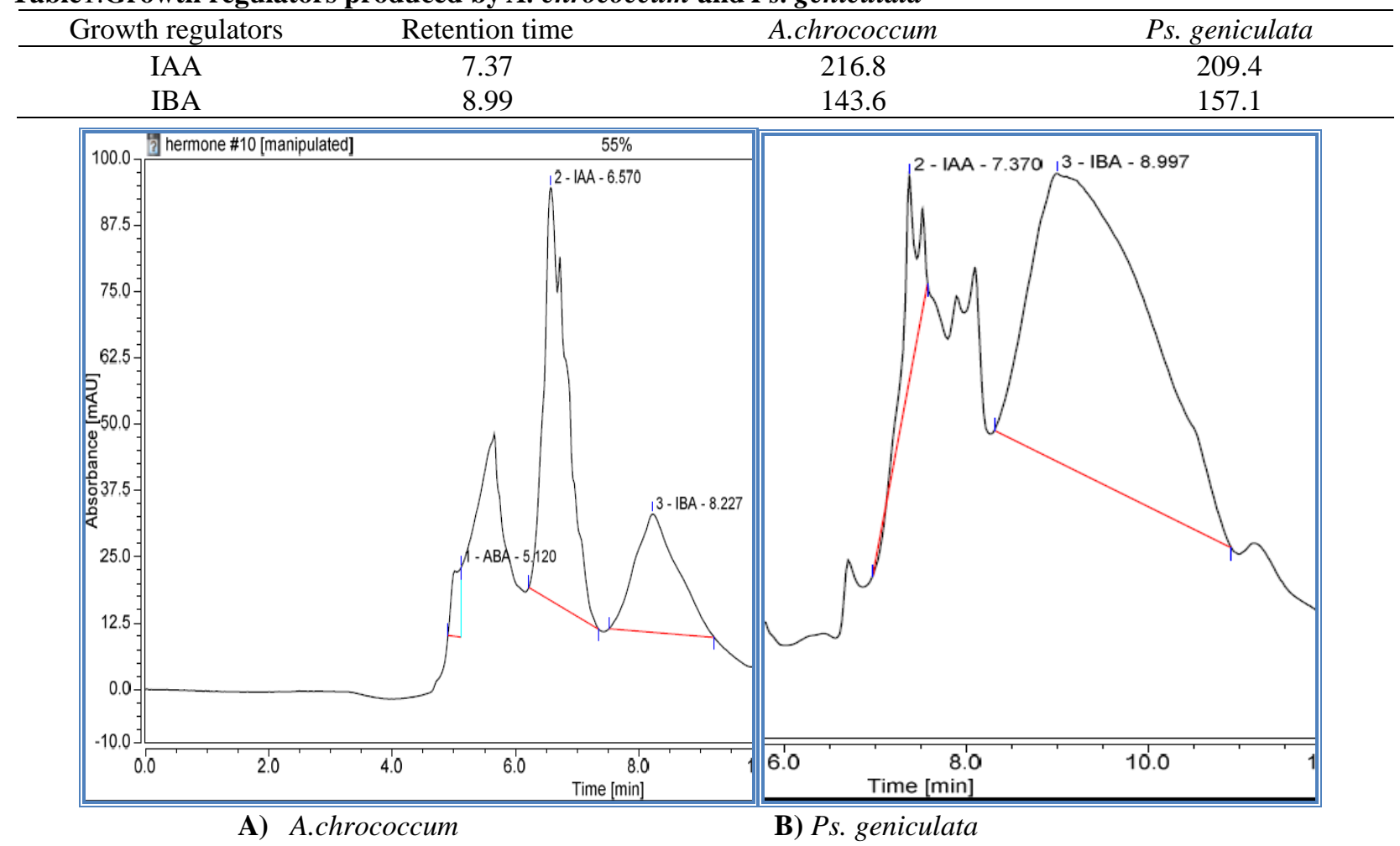

Figure 1. HPLC profiles of growth regulators in A. chrococcum and Ps. geniculata acceptable content of chromium in urban areas shouldn't exceed150-190 ppm. By summarizing up, soil experiment exhibited an elevation of salinity and high concentration of total $\mathrm{Cr}$ and Ni contents. While DTPAextractable in initial soil of heavy metal and trace elements were showed low values by order $20.02>14.8$ $>0.6004>0.336>0.1656>0.1536>0.1496>0.1352$ $>0.113>0.0104>0.0008 \mathrm{ppm}$ in $\mathrm{Fe}>\mathrm{Mn}>\mathrm{Al}>\mathrm{Cu}>$ $\mathrm{Zn}>\mathrm{Cr}>\mathrm{Ni}>\mathrm{Pb}>\mathrm{Co}>\mathrm{Mo}>\mathrm{Cd}$, respectively.

Chemical composition, heavy metals and trace elements content of irrigated water

Data in Table (3) showed that irrigated water was alkaline (pH 8) and exhibited a high EC value by 2800 $\mu \mathrm{mohs} / \mathrm{cm}$ and TDS by $1792 \mathrm{mg} / \mathrm{l}$, according to salinity classification of irrigation water by EPA (Environmental Protection Authority,1991). This meant that irrigation water was belonged to class 4 , in which EC was ranged between 1500 and $3500 \mu \mathrm{mohs} / \mathrm{cm}$ and TDS ranged between 2340 to $5470 \mathrm{mg} / \mathrm{l}$, soils irrigated by class 4 water must be permeable with adequate drainage, water must be applied in excess to provide considerable leaching and salt tolerant crops should be grown. Also, values of anions and cations were nearby values of Nile water analysis adopted by Hassan et al., (2002). 
Table 2. Physicochemical, heavy metal and trace elements analysis of initial cultivated soil in Baloza station (water extract 1:2.5)

\begin{tabular}{|c|c|c|c|c|c|c|c|c|c|c|c|c|c|c|c|c|}
\hline \multirow{2}{*}{ 竞 } & \multirow[t]{2}{*}{ pH } & \multirow{2}{*}{$\begin{array}{c}\text { E.C. } \\
(\mu \mathrm{mohs} / \mathrm{cm})\end{array}$} & \multirow[t]{2}{*}{$\mathrm{CaCo}_{3} \%$} & \multicolumn{4}{|c|}{$\begin{array}{c}\text { Cations } \\
\text { (ppm) }\end{array}$} & \multicolumn{5}{|c|}{$\begin{array}{c}\text { Anions } \\
(\mathbf{p p m})\end{array}$} & \multicolumn{3}{|c|}{$\begin{array}{l}\text { Particle size } \\
\text { distribution }\end{array}$} & \multirow{2}{*}{$\begin{array}{c}\text { Textural } \\
\text { class }\end{array}$} \\
\hline & & & & $\mathrm{Ca}^{2+}$ & $\mathrm{Mg}^{2+}$ & $\mathrm{Na}^{+}$ & $\mathbf{K}^{+}$ & $\mathrm{CO}_{3}{ }^{2-}$ & & $\mathrm{CO}_{3}^{-}$ & $\mathrm{Cl}^{-}$ & $\mathrm{SO}_{4}{ }^{2-}$ & Sand & Silt & Clay & \\
\hline $00-30$ & 7.9 & 1080 & 1 & 156 & 31.2 & 63.25 & 19.5 & - & & 24.41 & 106.5 & 381.6 & 91.12 & 2 & 6.88 & Sand \\
\hline \multicolumn{2}{|c|}{ Metal (ppm) } & Al & Cd & Co & \multicolumn{2}{|c|}{$\mathrm{Cr}$} & $\mathbf{C u}$ & $\mathbf{F}$ & \multicolumn{3}{|c|}{ Mn } & Mo & $\mathbf{N i}$ & \multicolumn{2}{|r|}{$\mathbf{P b}$} & Zn \\
\hline \multirow{3}{*}{\multicolumn{2}{|c|}{ Total }} & 2475 & 0.8 & 7.12 & \multicolumn{2}{|c|}{161.38} & 19.63 & & & \multicolumn{2}{|c|}{142.5} & 25.57 & 186.19 & \multicolumn{2}{|r|}{1.82} & 21.16 \\
\hline & & - & - & 3.65 & \multicolumn{2}{|c|}{ 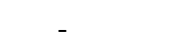 } & - & & 56 & \multicolumn{2}{|c|}{150} & - & 4.34 & & 11.96 \\
\hline & & 0.6004 & 0.0008 & 0.113 & & 1536 & 0.3366 & & .02 & 14. & & 0.0104 & 0.1496 & & 0.1352 & 0.1656 \\
\hline
\end{tabular}

Table 3. Physicochemical composition of El-Salam Canal irrigation water in Baloza Station

\begin{tabular}{|c|c|c|c|c|c|c|c|}
\hline \multirow{2}{*}{$\begin{array}{c}\text { Parameter } \\
\mathrm{pH}\end{array}$} & \multirow{2}{*}{$\begin{array}{c}\begin{array}{r}\text { Water } \\
\text { sample }\end{array} \\
8\end{array}$} & \multicolumn{2}{|c|}{$\begin{array}{l}\text { Permissible Limit } \\
\text { For irrigation }\end{array}$} & \multirow{2}{*}{$\begin{array}{c}\text { Parameter } \\
\mathrm{Al}\left(\mathrm{mgl}^{-1}\right)\end{array}$} & \multirow{2}{*}{$\begin{array}{c}\begin{array}{c}\text { Water } \\
\text { sample }\end{array} \\
\text { n.d. }\end{array}$} & \multicolumn{2}{|c|}{$\begin{array}{l}\text { Permissible Limit } \\
\text { For irrigation }\end{array}$} \\
\hline & & $6.5-8.5^{\mathrm{a}}$ & $6-9^{b}$ & & & - & $3^{\mathrm{b}}$ \\
\hline $\mathrm{EC}(\mathrm{mmohs} / \mathrm{cm})$ & 2.8 & $0.7-3^{\mathrm{a}}$ & - & $\mathrm{Cd}\left(\mathrm{mgl}^{-1}\right)$ & 0.01 & $0.01^{\mathrm{a}}$ & $0.05^{\mathrm{b}}$ \\
\hline TDS & 1792 & - & $2000^{\mathrm{b}}$ & $\mathrm{Co}\left(\mathrm{mgl}^{-1}\right)$ & n.d. & - & $2.0^{\mathrm{b}}$ \\
\hline $\operatorname{COD}\left(\mathrm{mgl}^{-1}\right)$ & 67 & $75-80^{\mathrm{WEF}}$ & $100^{\mathrm{b}}$ & $\mathrm{Cu}\left(\mathrm{mgl}^{-1}\right)$ & n.d. & $0.2^{\mathrm{a}}$ & $1.5^{\mathrm{b}}$ \\
\hline $\mathrm{Ca}^{2+}\left(\mathrm{mgl}^{-1}\right)$ & 80.16 & $0-400^{\mathrm{a}}$ & - & $\mathrm{Fe}\left(\mathrm{mgl}^{-1}\right)$ & n.d. & $5.0^{\mathrm{a}}$ & $1.5^{\mathrm{b}}$ \\
\hline $\mathrm{Mg}^{2+}\left(\mathrm{mgl}^{-1}\right)$ & 72.95 & $0-60^{\mathrm{a}}$ & - & $\operatorname{Mn}\left(\mathrm{mgl}^{-1}\right)$ & n.d. & - & $1.0^{\mathrm{b}}$ \\
\hline $\mathrm{Na}^{+}\left(\mathrm{mgl}^{-1}\right)$ & 407.08 & $0-920^{\mathrm{a}}$ & - & $\operatorname{Mo}\left(\mathrm{mgl}^{-1}\right)$ & 0.0048 & - & - \\
\hline $\mathrm{K}^{+}\left(\mathrm{mgl}^{-1}\right)$ & 31.37 & $0-2^{\mathrm{a}}$ & - & $\mathrm{Ni}\left(\mathrm{mgl}^{-1}\right)$ & 0.001 & - & $0.1^{\mathrm{b}}$ \\
\hline $\mathrm{CO}_{3}^{2-}\left(\mathrm{mgl}^{-1}\right)$ & - & - & - & $\mathrm{Pb}\left(\mathrm{mgl}^{-1}\right)$ & n.d. & - & $0.5^{\mathrm{b}}$ \\
\hline $\mathrm{HCO}_{3}^{-}\left(\mathrm{mgl}^{-1}\right)$ & 73.22 & - & - & Fecal & & & \\
\hline $\mathrm{Cl}^{-}\left(\mathrm{mgl}^{-1}\right)$ & 815.60 & - & - & contamination & 24 & \multirow{2}{*}{\multicolumn{2}{|c|}{$<200 \mathrm{MBN} / 100 \mathrm{ml}$}} \\
\hline $\mathrm{SO}_{4}{ }^{2-}\left(\mathrm{mgl}^{-1}\right)$ & 206.73 & - & - & $(\mathrm{MBN} / 100 \mathrm{ml})$ & & & \\
\hline
\end{tabular}

${ }^{\mathrm{a}} \mathrm{FAO}$ for irrigation water (Ayers and Wescot, 1994), WEF, Water Environment Federation (1998), ${ }^{\mathrm{b}} \mathrm{Law}$ 4/1994 revised in 2009

With regard to heavy metals and trace element concentrations, all elements were under the permissible levels of irrigation except that of $\mathrm{Cd}(0.01 \mathrm{ppm})$ which equal to irrigation limit. It was found that COD recorded $67 \mathrm{mg} / \mathrm{l}$ within range compared with Water Environment Federation (1998). Microbiological analysis of irrigation water revealed that fecal coliforms was $24 \mathrm{MPN} / 100 \mathrm{ml}$ which existed in a recommended level of irrigation water according to WHO guide (World Health Organization,2006). Othman et al., 2012 evaluated El-Salam canal along the first $55 \mathrm{~km}$ course in north Sinai, the potability of water was disputable along the first $30 \mathrm{~km}$, in view of its higher load of total bacteria, and total fecal coliforms, in addition to the chemical content of total salts, $\mathrm{Na}, \mathrm{Fe}$, and $\mathrm{Cd}$.

\section{Field experiment}

Vegetative growth, yield and oil content of castor plants

The field experiment was mainly conducted for enhancing the castor yield under El-Salam water irrigation to obtain oil for fuel production. For this target, both natural (biofertilizers) and synthetic growth hormones (IAA or IBA) were applied to castor plants. Generally, application of growth hormones had positive effect on all growth parameters of castor plants as indicated in Table (4). For foliar application, plants sprayed with IBA recorded the highest length while IAA recorded the highest oil content reaching (21.7\%) followed by IBA (15.5\%) comparing to control ones. Application of mixture of two growth hormones significantly increased number of branches, inflorescence and plant dry weight while no significant increase was recorded using single application of IAA or IBA compared to control.

Concerning to biofertilizers, plant treated with PGPB achieved significant increase for all traits recorded in plants. Biofertilizer treatment significantly increased inflorescence length, inflorescence weight, weight of 1000 seeds compared to control regardless the type of bacteria applied. Inoculation of Azotobacter chrococcum recorded significant increase in plant dry weight and oil content by (16\%) and by (9\%), respectively, followed by Pseudomonas geniculata compared to control. The most common explanation for the effect of rhizobacteria on plants is based on the production of phytohormones that alter plant metabolism and morphology, leading to improved 
mineral and water absorption (Bashan and Levanony, 1990).

Interaction between foliar application and biofertilizers had significant stimulatory effect on plant growth parameters, plants treated with IBA and Azotobacter chrococcum recorded the highest plant length, inflorescence weight, plant dry weight, weight of 1000 seeds and oil \% followed by other treatments compared to control. As reported by Nordstrom et al., (1991), IBA treatment resulted in increased IBA, IAA, and indole-3-acetylaspartic acid levels, the IAA content rapidly returned to control levels, whereas the IBA level remained high throughout the experimental period resulting higher plant inducing ability of IBA.

Spraying plants with mixture of growth hormone followed by single one (IAA or IBA) or inoculation with A.chrococcum followed by Pseudomonas geniculata significantly increased $\mathrm{N}$ and $\mathrm{P}$ uptake of

Table 4. Effect of foliar application, biotreatments and interaction on some crop yield and chemical measurements of castor plants cultivated under Sinai condition

\begin{tabular}{|c|c|c|c|c|c|c|c|c|c|c|c|c|c|}
\hline \multicolumn{2}{|c|}{ Treatments } & 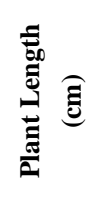 & $\begin{array}{l}\frac{\mathscr{E}}{0} \\
\frac{\pi}{0} \\
\dot{0} \\
\dot{0} \\
\dot{0}\end{array}$ & 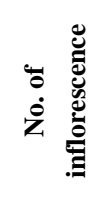 & 总 & 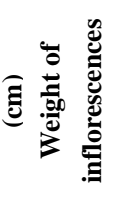 & 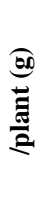 & 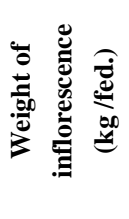 & 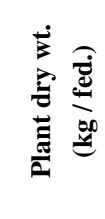 & 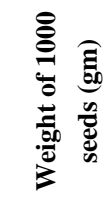 & 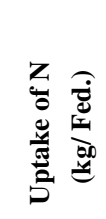 & 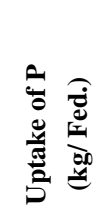 & $\overline{0}$ \\
\hline \multicolumn{14}{|c|}{ Effect of foliar application } \\
\hline \multicolumn{2}{|c|}{ IAA } & 144.4 & 3.56 & 6.89 & 27.0 & 146.66 & & 1540.0 & 2870.0 & 269.8 & 11.98 & 14.39 & 52.33 \\
\hline \multicolumn{2}{|l|}{ IBA } & 156.9 & 3.33 & 6.33 & 30.6 & 143.00 & & 1501.5 & 3711.9 & 272.0 & 13.59 & 10.46 & 49.67 \\
\hline \multicolumn{2}{|l|}{ Mixture } & 136.8 & 5.44 & 9.11 & 28.7 & 207.11 & & 2174.7 & 3911.8 & 270.7 & 16.52 & 20.06 & 50.00 \\
\hline \multicolumn{2}{|l|}{ Control } & 116.4 & 5.22 & 7.00 & 28.1 & 125.56 & & 1481.7 & 2237.2 & 275.8 & 08.64 & 03.35 & 43.00 \\
\hline \multicolumn{2}{|c|}{ LSD0.05 } & 10.24 & 1.78 & 2.3 & 2.4 & 21.35 & & 317.5 & 1209 & N.S & 5.23 & 1.25 & 0.01 \\
\hline \multicolumn{14}{|c|}{ Effect of Biofertilizar:- } \\
\hline \multicolumn{2}{|c|}{ A.chrococcum } & 141.1 & 4.50 & 7.92 & 28.78 & 167.9 & & 1823.5 & 3672.1 & 288.8 & 14.90 & 20.23 & 51.50 \\
\hline \multicolumn{2}{|c|}{ Ps. geniculata } & 144.0 & 4.42 & 7.83 & 30.19 & 163.5 & & 1778.8 & 2905.2 & 284.4 & 11.93 & 08.26 & 47.50 \\
\hline \multicolumn{2}{|c|}{ Control } & 140.7 & 4.25 & 6.25 & 26.91 & 135.3 & & 1421.0 & 2971.2 & 248.9 & 11.22 & 07.70 & 47.25 \\
\hline \multicolumn{2}{|c|}{ LSD0.05 } & N.S & N.S & N.S & 2.938 & 16.04 & & 132.1 & 656.0 & 37.3 & 2.83 & 1.57 & 0.01 \\
\hline \multicolumn{14}{|c|}{ Effect of interaction:- } \\
\hline \multicolumn{14}{|c|}{ Foliar Biotreatment } \\
\hline \multirow[t]{3}{*}{ Without } & A.chrococcum & 146 & 4.33 & 10 & 24.2 & 155.0 & & 1627.5 & 2956.5 & 246.0 & 13.32 & 18.63 & 53 \\
\hline & Ps. geniculata & 143 & 3.66 & 05 & 30.43 & 157.67 & & 1655.5 & 2539.8 & 314.0 & 10.17 & 12.70 & 52 \\
\hline & Control & 144 & 2.66 & 05 & 26.47 & 127.33 & & 1337.0 & 3113.6 & 172.67 & 12.45 & 11.83 & 52 \\
\hline \multirow[t]{3}{*}{ IAA } & A.chrococcum & 170 & 3.67 & 08 & 28.03 & 160.00 & & 1680.0 & 4551.5 & 279.67 & 15.95 & 12.29 & 48 \\
\hline & Ps. geniculata & 153 & 3.33 & 06 & 33.47 & 165.33 & & 1736.0 & 3489.0 & 293.0 & 13.97 & 10.12 & 49 \\
\hline & Control & 148 & 3.00 & 05 & 30.33 & 103.67 & & 1088.5 & 3095.4 & 243.33 & 10.84 & 8.98 & 52 \\
\hline \multirow[t]{3}{*}{ IBA } & A.chrococcum & 122 & 5.33 & 10 & 30.33 & 230.00 & & 2415.0 & 5149.8 & 311.67 & 23.20 & 33.38 & 59 \\
\hline & Ps. geniculata & 153 & 5.33 & 09 & 29.83 & 201.67 & & 2023.0 & 3178.6 & 267.0 & 12.73 & 07.31 & 46 \\
\hline & Control & 135 & 5.67 & 09 & 26.00 & 189.67 & & 1788.5 & 3407.6 & 257.33 & 13.64 & 07.50 & 45 \\
\hline \multirow[t]{4}{*}{ Mix. } & A.chrococcum & 127 & 4.67 & 04 & 32.53 & 126.67 & & 1571.5 & 2030.3 & 318.00 & 7.11 & 04.67 & 46 \\
\hline & Ps. geniculata & 126 & 5.33 & 11 & 27.83 & 129.33 & & 1606.5 & 2413.3 & 263.67 & 10.87 & 02.90 & 42 \\
\hline & Control & 96 & 5.67 & 06 & 24.83 & 120.67 & & 1267.0 & 2267.9 & 245.67 & 7.97 & 02.50 & 41 \\
\hline & SD0.05 & 20.4 & 1.77 & 4.347 & 5.88 & 32.07 & & 264.1 & 1312 & 74.61 & 5.66 & 3.14 & 0.02 \\
\hline
\end{tabular}

plants. Auxins, Indole-3-acetic acid , 4-chloroindole-3acetic acid and indole-3-butyric acid significantly improved the nitrogen metabolism, photosynthesis and yield of the chickpea (Qaiser et al .,2009; El- Baha et al .2016 ).The highest result was recorded by treating plants with IBA and Azotobacter chrococcum together.

Trace elements and heavy metals contents in castor plant shoot

Data in Table (5), clearly indicated that IAA and/or IBA treatments significantly increased metal shoot contents in castor plants irrigated by El-Salam canal relative to untreated ones. The most pronounced treatment in the main factor was mixture application (50 mg/l IAA + 50 mg/l ABA) in $\mathrm{Al}, \mathrm{Co}, \mathrm{Cr}, \mathrm{Cu}, \mathrm{Fe}, \mathrm{Mn} \&$ Mo by 573.13, 0.869, 11.07, 31.532, 813.12, 407.78 and $2.17 \mathrm{mg} / \mathrm{kg}$; respectively. 
Table 5. Effect of the foliar application, bio-fertilizer and their interaction on heavy metals and trace elements of castor plant shoots cultivated under Sinai condition irrigated with El-Salam Canal

\begin{tabular}{|c|c|c|c|c|c|c|c|c|c|c|c|}
\hline & Treatments & Al & $\mathbf{C r}$ & $\mathbf{P b}$ & $\mathbf{N i}$ & $\mathbf{C u}$ & $\mathbf{F e}$ & Mn & Mo & Co & Zn \\
\hline \multicolumn{12}{|c|}{ Effect of foliar application:- } \\
\hline & IAA & 441.44 & 6.027 & 3.936 & 2.617 & 21.271 & 720.49 & 124.22 & 1.467 & 0.563 & 18.016 \\
\hline & IBA & 534.73 & 6.358 & 4.313 & 1.633 & 18.142 & 617.01 & 138.23 & 1.517 & 0.638 & 28.017 \\
\hline & Mixture & 573.13 & 11.07 & 3.563 & 2.022 & 31.532 & 813.12 & 407.78 & 2.170 & 0.869 & 23.300 \\
\hline & Control & 317.18 & 2.186 & 1.890 & 1.220 & 11.723 & 360.36 & 106.94 & 0.507 & 0.382 & 13.110 \\
\hline & LSD 0.05 & 1.24 & 0.985 & 0.126 & 0.109 & 0.073 & 36.1 & 2.85 & 0.063 & 0.182 & 0.163 \\
\hline \multicolumn{12}{|c|}{ Effect of Biofertilizar:- } \\
\hline & chrococcum & 560.60 & 7.366 & 3.873 & 2.442 & 27.359 & 703.53 & 226.29 & 1.575 & 0.763 & 22.255 \\
\hline & s. geniculata & 487.32 & 8.111 & 3.701 & 1.952 & 19.096 & 798.20 & 243.25 & 1.942 & 0.603 & 22.600 \\
\hline & Control & 391.95 & 3.753 & 2.703 & 1.225 & 15.574 & 381.50 & 113.33 & 0.763 & 0.473 & 16.977 \\
\hline & LSD 0.05 & 0.521 & N.S. & 0.098 & 0.061 & 0.061 & 17.87 & 1.19 & 0.039 & 0.102 & 0.125 \\
\hline \multicolumn{12}{|c|}{ Effect of interaction:- } \\
\hline Foliar & Biotreatment & & & & & & & & & & \\
\hline \multirow{4}{*}{$\begin{array}{l}\text { With } \\
\text { out }\end{array}$} & A.chrococcum & 557.0 & 8.25 & 5.44 & 3.05 & 24.24 & 1061 & 145.35 & 2.80 & 0.84 & 19.40 \\
\hline & Ps. geniculata & 421.1 & 5.85 & 3.65 & 2.70 & 19.93 & 745.0 & 118.03 & 0.75 & 0.44 & 17.70 \\
\hline & Control & 346.2 & 3.98 & 2.72 & 2.10 & 19.64 & 355.5 & 109.28 & 0.85 & 0.41 & 16.95 \\
\hline & A.chrococcum & 597.0 & 6.21 & 4.25 & 2.30 & 24.31 & 715.4 & 119.00 & 0.75 & 0.72 & 33.50 \\
\hline \multirow[t]{3}{*}{ IAA } & Ps. geniculata & 553.0 & 7.12 & 5.37 & 1.50 & 18.05 & 777.7 & 173.52 & 2.60 & 0.52 & 32.85 \\
\hline & Control & 454.2 & 5.75 & 3.32 & 1.10 & 12.07 & 358.0 & 122.17 & 1.20 & 0.67 & 17.70 \\
\hline & A.chrococcum & 603.4 & 12.5 & 3.65 & 3.07 & 49.07 & 619.3 & 531.00 & 2.15 & 1.06 & 22.10 \\
\hline \multirow[t]{3}{*}{ IBA } & Ps. geniculata & 610.0 & 17.4 & 3.72 & 2.25 & 24.70 & 1323.0 & 571.00 & 3.75 & 1.04 & 25.65 \\
\hline & Control & 506.0 & 3.27 & 3.32 & 0.75 & 20.83 & 497.0 & 121.33 & 0.75 & 0.50 & 22.15 \\
\hline & A.chrococcum & 325.0 & 2.51 & 2.15 & 1.35 & 11.82 & 418.4 & 109.80 & 0.66 & 0.43 & 14.02 \\
\hline \multirow[t]{3}{*}{ Mix. } & Ps. geniculata & 365.2 & 2.04 & 2.07 & 1.36 & 13.70 & 347.1 & 110.47 & 0.67 & 0.41 & 14.20 \\
\hline & Control & 261.4 & 2.01 & 1.45 & 0.95 & 9.65 & 315.5 & 100.55 & 0.25 & 0.31 & 11.11 \\
\hline & LSD 0.05 & 1.0 & N.S. & 0.2 & 0.12 & 0.12 & 35.8 & 2.39 & 0.08 & 0.21 & 0.25 \\
\hline
\end{tabular}

Furthermore, the highest values of $\mathrm{Pb} \& \mathrm{Zn}$ contents by 4.313 and $28.017 \mathrm{mg} / \mathrm{l}$; respectively were obtained from the application of IBA. And for Ni content by 2.617 $\mathrm{mg} / \mathrm{kg}$ was gotten from the spraying application of IAA. MacDonald, (1997) mentioned that IAA had range of effects on many processes such as cell division, vascular tissue differentiation, root initiation, flowering, inflorescence setting, ripening, senescence and gravitropism. Amin et al., (2006) mentioned that foliar application of indole-3-butyric acid increased vegetative growth of maize plants at the different stages of growth. In this concern, the stimulatory effect of IAA and IBA as foliar application in this study may be attributed to the increasing in growth criteria of castor plants.

The inoculation of Plant Growth Promoting Rhizobacteria (A.chrococcum or Ps. geniculata) as subfactor on trace and heavy metal contents in castor shoot plants were showed in Table (5). Plants treated with A.chrococcum showed the highest significant contents of $\mathrm{Al}, \mathrm{Co}, \mathrm{Cr}, \mathrm{Cu}, \mathrm{Ni}$ and $\mathrm{Pb}$ by 560.6, 0.763, 7.366, $27.359,2.442 \& 3.873 \mathrm{mg} / \mathrm{kg}$, respectively. Once largely unexplored option involves the effects of soil microbiota and plant associated bacteria in particular, on heavy metal speciation, phytoavailability, uptake and

toxicity to their host plants (White et al., 1997). On the other hand, the highest significant increase recorded by Ps. geniculata application were $\mathrm{Fe}, \mathrm{Mn}, \mathrm{Mo} \& \mathrm{Zn}$ achieving 798.20, 243.25, 1.942 \& $22.6 \mathrm{mg} / \mathrm{kg}$; respectively. In this concern, Badawy, (2005) revealed that soil bio-fertilizers have the potential to alter the amount of heavy metal uptake and accumulation in plants, it was found that, the maximum increase in $\mathrm{Zn}$ content of canola plant as a whole was $205 \%$ due to A.chrococcum inoculation compared with their control.

The combined treatments enhanced the above mentioned trace and heavy metal contents in most cases compared with the individual effect, except in Fe, Mn and Mo contents. It might be attributed to a synergistic effect between foliar application and PGPR effects. The interaction between microorganisms, plant roots and amendments might have a greater impact on both the increase of nutrient uptake and migration of metal uptake (Smith, 1994).

By comparing the results obtained from this study with range of elemental concentrations in dried plant $\left(\mathrm{mgkg}^{-1}\right)$ as in Table (6), according to Reeves and Baker, (2000) it was found that heavy metal and trace element concentrations were existed in a normal range 
concentration and it was noticed that, accumulation of these metal concentration in face of the low availability of these metals in soil solution.

Table 6. Range of elemental concentrations in dried plant $\left(\mathrm{mgkg}^{-1}\right)$ according to Reeves and Baker, (2000).

\begin{tabular}{cccc}
\hline Element & Low & Normal & High \\
\hline $\mathrm{Fe}$ & 10 & $60-600$ & 2500 \\
$\mathrm{Mn}$ & 5 & $20-400$ & 2000 \\
$\mathrm{Zn}$ & 5 & $20-400$ & 2000 \\
$\mathrm{Ni}$ & 0.2 & $1-10$ & 100 \\
$\mathrm{Co}$ & 0.01 & $0.03-2$ & 20 \\
$\mathrm{Cr}$ & 0.05 & $0.2-5$ & 50 \\
$\mathrm{Cu}$ & 1 & $5-25$ & 100 \\
\hline
\end{tabular}

Trace elements and heavy metals of soil at the end of experiment

It was noticed from Table (7) that mixture of IAA + IBA showed the highest values of available heavy metal contents in soil solution except in $\mathrm{Pb}, \mathrm{Zn} \& \mathrm{Cu}$. On other hand, inoculation treatment of Ps.geniculata decreased $\mathrm{Al}, \mathrm{Cr}$ and $\mathrm{Pb}$ soil availability, but inoculation treatment by A.chrococcum increase, $\mathrm{Cu}$,
Fe, Mn, Mo and $\mathrm{Zn}$ soil availability than control. Interaction effect between both treatments showed a significant superiority of treatment by usage of the mixture of foliar application (IAA + IBA) and A.chrococcum inoculation. Generally, it was noticed a low availability of metals comparing with total soil content as in Table (7) which might be attributed to soil salinity. Soil factors as $\mathrm{pH}, \mathrm{EC}, \mathrm{CaCo}_{3}$, organic matter, clay and silt contents and inorganic amorphous materials $\left(\mathrm{SiO}_{2}, \mathrm{Al}_{2} \mathrm{O}_{3}\right.$ and $\left.\mathrm{Fe}_{2} \mathrm{O}_{3}\right)$ were affected to heavy metals availability (Abdel-Rahman and ElDemerdashe, 2003). The relative mobility of some trace elements in soils as influenced by soil $\mathrm{pH}$ was summarized by Adriano, (1986) that in acid soils ( $\mathrm{pH}$ 4.2 to 6.6 ), $\mathrm{Cd}, \mathrm{Hg}, \mathrm{Ni}$ and $\mathrm{Zn}$ were relatively mobile, As and $\mathrm{Cr}$ moderately mobile and $\mathrm{Cu}, \mathrm{Pb}$ and $\mathrm{Se}$ were slowly mobile. In neutral to alkaline soils $(\mathrm{pH} 6.7$ to 7.8) Arsenic and $\mathrm{Cr}$ are relatively mobile while $\mathrm{Be}, \mathrm{Cd}$, $\mathrm{Hg}$ and $\mathrm{Zn}$ were moderately mobile. Total $\mathrm{Cd}$ content in calcareous soils was negatively correlated with $\mathrm{pH}(\mathrm{El}-$ Demerdashe and Abdel-Rahman, 1997).

Table 7.Effect of the foliar application, biofertilizer and their interaction on heavy metals and trace elements of soil at the end of experiment conducted under Sinai condition and irrigated with El-Salam Canal

\begin{tabular}{|c|c|c|c|c|c|c|c|c|c|c|c|}
\hline \multirow{2}{*}{\multicolumn{2}{|c|}{$\begin{array}{c}\text { Treatments } \\
\text { Effect of foliar application }\end{array}$}} & \multirow[t]{2}{*}{ Al } & \multirow[t]{2}{*}{$\mathrm{Cr}$} & \multirow[t]{2}{*}{$\mathbf{P b}$} & \multirow[t]{2}{*}{$\mathrm{Ni}$} & \multirow[t]{2}{*}{$\mathbf{C u}$} & \multirow[t]{2}{*}{$\mathbf{F e}$} & \multirow[t]{2}{*}{ Mn } & \multirow[t]{2}{*}{ Mo } & \multirow[t]{2}{*}{ Co } & \multirow[t]{2}{*}{$\mathbf{Z n}$} \\
\hline & & & & & & & & & & & \\
\hline & IAA & 1.74 & 0.196 & 0.189 & 0.177 & 0.753 & 29.77 & 31.21 & 0.017 & 0.14 & 0.422 \\
\hline & IBA & 2.75 & 0.179 & 0.186 & 0.207 & 1.302 & 28.19 & 34.37 & 0.016 & 0.14 & 0.566 \\
\hline & Mixture & 2.80 & 0.202 & 0.183 & 0.202 & 1.015 & 35.85 & 35.71 & 0.014 & 0.16 & 0.362 \\
\hline & Control & 1.15 & 0.169 & 0.144 & 0.267 & 0.562 & 21.96 & 18.35 & 0.012 & 0.24 & 0.227 \\
\hline & LSD 0.05 & 0.052 & 0.001 & 0.001 & N.S. & 0.001 & 0.002 & 0.06 & 0.001 & N.S. & 0.001 \\
\hline \multicolumn{12}{|c|}{ Effect of Biofertilizar:- } \\
\hline & chrococcum & 2.067 & 0.191 & 0.175 & 0.273 & 1.198 & 32.397 & 38.375 & 0.018 & 0.229 & 0.494 \\
\hline & s. geniculata & 2.236 & 0.196 & 0.970 & 0.191 & 0.885 & 29.080 & 27.630 & 0.014 & 0.143 & 0.400 \\
\hline & Control & 2.027 & 0.173 & 0.155 & 0.176 & 0.671 & 25.358 & 23.726 & 0.013 & 0.133 & 0.288 \\
\hline & LSD 0.05 & 0.055 & 0.001 & 0.001 & N.S. & 0.001 & 0.001 & 0.027 & 0.001 & N.S. & 0.001 \\
\hline \multicolumn{12}{|c|}{ Effect of interaction:- } \\
\hline Foliar & Biotreatment & & & & & & & & & & \\
\hline \multirow{3}{*}{$\begin{array}{l}\text { Witho } \\
\text { ut }\end{array}$} & A.chrococcum & 2.330 & 0.204 & 0.172 & 35.20 & 0.912 & 35.22 & 40.20 & 0.025 & 0.144 & 0.475 \\
\hline & Ps. geniculata & 1.677 & 0.213 & 0.227 & 29.04 & 0.713 & 29.04 & 28.5 & 0.014 & 0.148 & 0.472 \\
\hline & Control & 1.219 & 0.172 & 0.170 & 25.07 & 0.634 & 25.07 & 24.94 & 0.013 & 0.128 & 0.318 \\
\hline \multirow{4}{*}{ IAA } & A.chrococcum & 1.053 & 0.192 & 0.202 & 30.27 & 1.469 & 30.27 & 37.78 & 0.020 & 0.147 & 0.864 \\
\hline & Ps. geniculata & 3.417 & 0.188 & 0.199 & 28.92 & 1.379 & 28.92 & 34.24 & 0.015 & 0.145 & 0.495 \\
\hline & Control & 3.782 & 0.156 & 0.156 & 25.40 & 1.057 & 25.40 & 31.08 & 0.013 & 0.128 & 0.338 \\
\hline & A.chrococcum & 3.150 & 0.194 & 0.181 & 39.30 & 1.605 & 39.30 & 54.66 & 0.016 & 0.163 & 0.437 \\
\hline \multirow[t]{2}{*}{ IBA } & Ps. geniculata & 3.067 & 0.215 & 0.216 & 37.46 & 1.808 & 37.46 & 30.16 & 0.014 & 0.152 & 0.355 \\
\hline & Control & 2.180 & 0.198 & 0.152 & 30.78 & 0.633 & 30.78 & 22.32 & 0.013 & 0.155 & 0.295 \\
\hline \multirow{4}{*}{ Mix. } & A.chrococcum & 1.733 & 0.174 & 0.143 & 24.80 & 0.687 & 24.80 & 20.86 & 0.012 & 0.463 & 0.202 \\
\hline & Ps. geniculata & 0.782 & 0.168 & 0.147 & 20.90 & 0.639 & 20.90 & 17.62 & 0.012 & 0.127 & 0.277 \\
\hline & Control & 0.928 & 0.164 & 0.143 & 20.18 & 0.361 & 20.18 & 16.57 & 0.012 & 0.119 & 0.202 \\
\hline & LSD 0.05 & 0.11 & 0.002 & 0.002 & 0.29 & 0.002 & 0.002 & 0.002 & 0.002 & 0.29 & 0.002 \\
\hline
\end{tabular}




\section{Microbiological characteristics}

For dehydrogenase activity, as indicated from Table (8), spraying plants with mixture of growth hormones recorded the highest significant increase followed by that of IBA and then IAA compared to control. On the other hand, treatments plants with biofertilizers had a significant positive effect on the enzyme activity, inoculation plants with Azotobacter chrococcum achieved higher result than that of Pseudomonas geniculata .Interaction between growth hormones and biofertilizers applications recorded the highest increase in enzyme activity using mixture of growth hormones and Azotobacter chrococcum or Pseudomonas geniculata. Increased dehydrogenase enzyme activity is proportionally linked to microbial function (Caldwell, 2005) leading to improved nutrient cycling and availability, which favors root growth, promotes beneficial plant-microbial interactions

Results of microbial counts were compatible to that of enzyme assayed. A remarkable increase in the microbial population of rhizospheric regions was detected in all treated plants compared to those before planting. Application of biofertilizers or growth hormones regardless the type used caused a remarkable increase in total microbial populations, Azotobacter and Pseudomonas counts in the rhizosphere. Inoculation with the plant growth promoting rhizobacteria had stimulation effect on the population of rhizosphere microorganism and increased their numbers by more than $50 \%$ at the end of the experiment comparing with the number recorded before planting (Ashrafuzzaman et al., 2009).

Table8. Effect of foliar application, biotreatments and interaction on microbiological characteristics of castor plants cultivated under Sinai condition

\begin{tabular}{|c|c|c|c|c|c|}
\hline \multirow[t]{2}{*}{ Foliar } & \multirow[t]{2}{*}{ Biotreatments } & \multicolumn{4}{|c|}{ Microbiological analyses } \\
\hline & & $\begin{array}{c}\text { Dehydrogenase } \\
\text { ( } \mu \mathrm{g} \text { TPF/g } \\
\text { drysoil/24 h) }\end{array}$ & $\begin{array}{c}\text { Total } \\
\text { microbial } \\
\text { count }(\mathrm{N} / \mathrm{No}) *\end{array}$ & $\begin{array}{l}\text { Azotobacter } \\
\text { count (N/No)* }\end{array}$ & $\begin{array}{l}\text { Pseudomonas } \\
\text { count (N/No)* }\end{array}$ \\
\hline \multirow[t]{3}{*}{ Without } & A.chrococcum & 0.24 & 1.8 & 1.4 & 1.6 \\
\hline & Ps. geniculata & 0.20 & 1.9 & 1.1 & 2.3 \\
\hline & Control ( No) & 0.17 & 1 & 1 & 1 \\
\hline \multirow[t]{3}{*}{ IAA } & A.chrococcum & 0.25 & 1.9 & 1.6 & 2 \\
\hline & Ps. geniculata & 0.21 & 1.6 & 1.2 & 2.7 \\
\hline & Control & 0.21 & 1.1 & 1.2 & 2.3 \\
\hline \multirow[t]{3}{*}{ IBA } & A.chrococcum & 0.27 & 2.2 & 1.5 & 2.4 \\
\hline & Ps. geniculata & 0.25 & 1.7 & 1 & 3.1 \\
\hline & Control & 0.254 & 1.33 & 1 & 2.4 \\
\hline \multirow[t]{3}{*}{ Mix. } & A.chrococcum & 0.22 & 3.1 & 1.7 & 2.7 \\
\hline & Ps. geniculata & 0.244 & 3.1 & 1.4 & 2.6 \\
\hline & Control & 0.18 & 2.6 & 1.2 & 1.9 \\
\hline
\end{tabular}

Pearson's Product-Moment correlation analysis between some yield characters in castor plants and availability of trace and heavy metals in rhizosphere soil were presented in Table (9). Uptake of nitrogen in castor plants was showed a positive and significant correlation with $\mathrm{Cu}, \mathrm{Mn}$ by 0.632 and 0.640, respectively. However, uptake of $\mathrm{P}$ was highly positive significant with available of $\mathrm{Cd}, \mathrm{Mn}$ in soil by 0.737 and 0.879 ; respectively. In the experiments of Simon (1998), neither low nor high heavy metal had modified the uptake of nitrogen, phosphorus or potassium by sunflower plants. In this concern, Bedbabis, et al., (2015) stated that oil content was not affected significantly by water quality. In addition to, a positive significant correlation coefficient with $\mathrm{Co}, \mathrm{Cu}$ and $\mathrm{Fe}$ A worth mention that, weight of 1000 seeds of castor plants were exhibited a negative non-significant correlation with $\mathrm{Al}, \mathrm{Cr}, \mathrm{Fe}, \mathrm{Mo}, \mathrm{Ni}, \mathrm{Pb} \& \mathrm{Zn}$. This implied that, seed yield had an adverse with heavy metal pollution thus it was leads to a reduction in the yield oil. A highly positive correlation was observed between oil\% and uptake of $\mathrm{P}$ and available of $\mathrm{Cd}$ and Mn in soil by $0.889,0.748,0.839$, respectively, while a positive significant at 0.05 with $\mathrm{Cu}$ and $\mathrm{Fe}$ by 0.627 and 0.612, respectively. Application of phosphorus is known to enhance lipids metabolism, subsequently increased seed oil content (\%) as reported by Kabesh et al. (1989) .Phosphorus application significantly increased the seed yield and oil content (Tanwar and Shaktawat, 2003). by $0.614,0.648$ and 0.673 , respectively were detected.

* N/No: Bacteria count of treated plant / Bacteria count of untreated plant (control). 


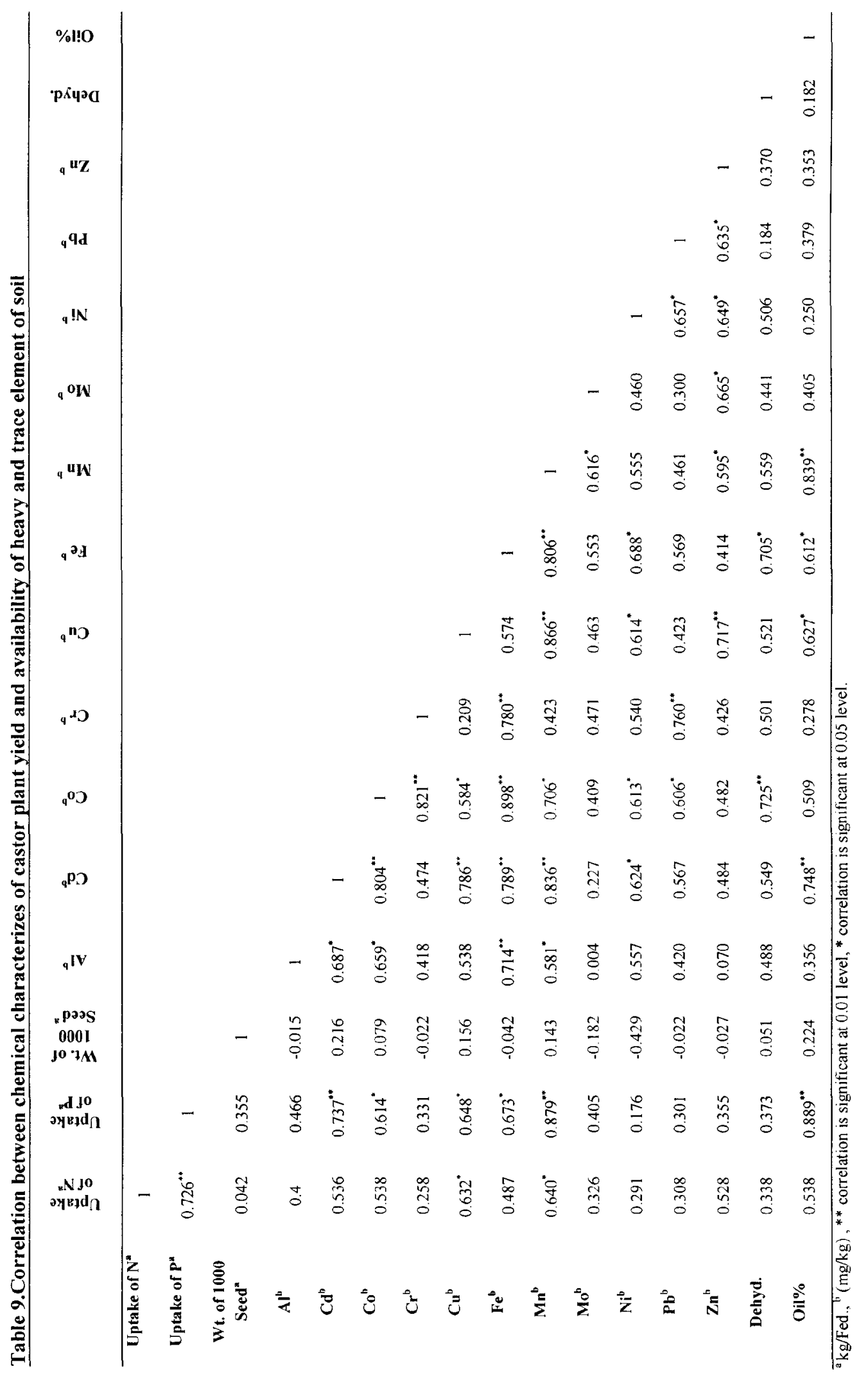




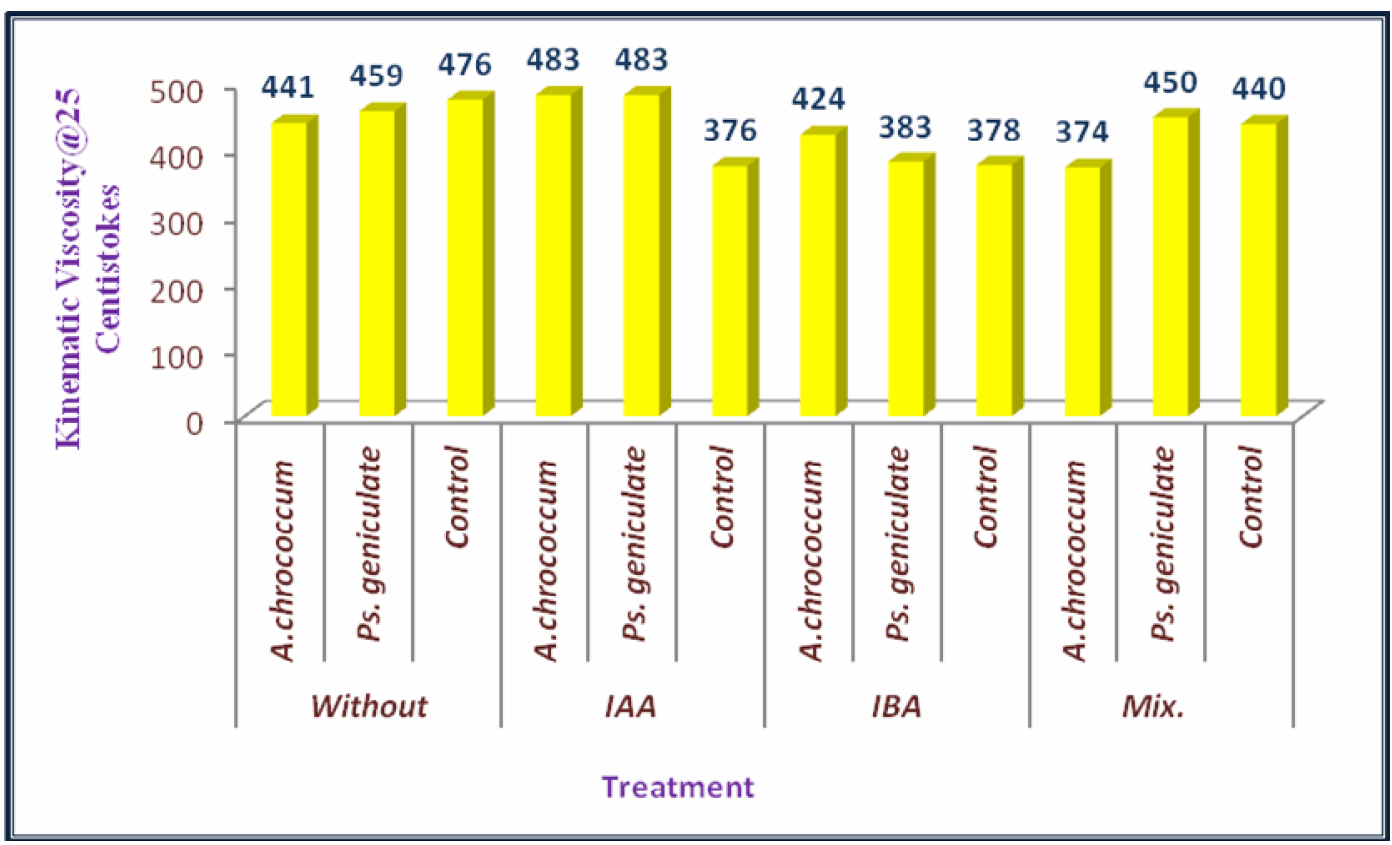

Figure 2. Viscosity of castor oil samples

Dehydrogenase enzyme had a positive highly significant correlation with available Co in soil by 0.72 and with available Fe in soil (at 0.05 level) by 0.705 . The microbial parameters were mostly negatively significantly correlated with the contents of $\mathrm{Cu}, \mathrm{Zn}, \mathrm{Cd}$ and $\mathrm{Ni}$ in the paddy fields, fully suggesting that the heavy metals had toxic effects on microbial processes (Hu, et al., 2014). Furthermore, the principal component analysis and cluster analysis indicated that the activities of dehydrogenase and microbial biomass carbon were the most sensitive to the toxicity of heavy metals and could be used as eco-indicators of soil pollution in the study area. Tan et al., (2017) reported that dehydrogenase activity (DHA) is an important indicator of heavy metal toxicity in contaminated soil. The contradiction which occurred between this study about positive correlation and other study may attribute to low concentration of heavy metals which present in cultivated soil.

\section{Crude Oil viscosity}

Measuring the viscosity of castor oil samples before biodiesel synthesis was helpful to evaluate the quality of the raw material for biodiesel production. No remarkable variations in the viscosity of oil samples was recorded among treated or untreated castor plants , neither growth hormones nor biofertilizers was effective in reducing the oil viscosity as indicated in Figure(2). The results indicated that the viscosity of all oil samples at $25^{\circ} \mathrm{C}$ was extremely higher than that of other vegetable oils and also petroleum diesel, this was explained by Okullo et al. (2012) as the lack of double bond in triglyceride molecule plus long hydrocarbon tail on fatty acid molecule contribute to high viscosity of castor oil. This result was compatible with that of Tina et al. (2012) who found that vegetable oils as alternative engine fuels are extremely viscous with viscosities ranging from 10 to 17 times greater than petroleum diesel fuel and can be reduced by transesterification with alcohols and converting into biodiesel. The purpose of the transesterification process of the oil to its corresponding fatty ester (biodiesel) is to lower the viscosity of the oil (Demirbas, 2007). Three oil samples, one with the lowest viscosity (oil extracted from plants treated with Azotobacter chrococcum and mixture of $I A A$ and IBA ) and one with the highest one (oil extracted from plants treated with IAA and Azotobacter chrococcum) in addition to control one were selected for biodiesel production.

\section{Characterization of castor oil biodiesel}

Esterification of three selected castor oil samples was performed and so, biodiesel was produced. Characterization of some physicochemical aspects of castor oil biodiesel were assayed, i.e., viscosity, flash point, cloud point, carbon residue, specific gravity and specific heat to evaluate their viability for using as biofuel.

As indicated in Table (10), a remarkable decrease in the viscosity of all oil samples was recorded reaching about $300 \%$ reduction compared to crude oils. Chemical conversion of the oil to its corresponding fatty ester is the most promising solution to the high viscosity problem (Panwar et al.,2010). In comparison to ASTM standards, only flash and cloud point of the three biodiesel samples conformed to the standard ranges 
Table 10. Characterization of castor biodiesel

\begin{tabular}{ccccccc}
\hline $\begin{array}{c}\text { Biodiesel } \\
\text { samples }\end{array}$ & $\begin{array}{c}\text { Carbon } \\
\text { Residue\% }\end{array}$ & $\begin{array}{c}\text { Density } \\
\left(\mathbf{k g} / \mathbf{m}^{\mathbf{3}}\right)\end{array}$ & $\begin{array}{c}\text { Specific Heat } \\
(\mathbf{k J} / \mathbf{k g} / \mathbf{K})\end{array}$ & $\begin{array}{c}\text { Cloud } \\
\text { Point }{ }^{\mathbf{0}} \mathbf{C}\end{array}$ & $\begin{array}{c}\text { Flash } \\
\text { Point } \mathbf{~}^{\mathbf{C}}\end{array}$ & $\begin{array}{c}\text { Kinematic } \\
\text { Viscosity@ 25 } \\
\text { Centistokes }\end{array}$ \\
\hline $\mathrm{B}_{1}$ & 2.12 & 821 & 0.081 & 2.1 & 131 & 101 \\
$\mathrm{~B}_{2}$ & 3.14 & 615 & 0.062 & 2 & 112 & 106 \\
$\mathrm{~B}_{\text {Control }}$ & 2.1 & 610 & 0.06 & 2.1 & 116 & 108 \\
\hline
\end{tabular}

$\mathrm{B}_{1}$ : Biodiesel obtained from castor plants treated with IAA and A.chrococcum

$\mathrm{B}_{2}$ : Biodiesel obtained from castor plants treated with Azotobacter chrococcum and mixture of IAA and IBA

$\mathrm{B}$ Control: Biodiesel obtained from untreated castor plants (Control)

which is $131^{\circ} \mathrm{C}$ for flash point and -2 to $12^{\circ} \mathrm{C}$ for cloud point. As flash point represents the temperature at which the fuel becomes potentially flammable mixture when exposed to a spark or flame, and is a very significant property in engine performance, cloud point is a temperature at which a haze of crystals appears in the fuel under test conditions.

On other hand, viscosity, carbon residue and heat resistance of three biodiesel samples were higher than that of the ASTM standards of biodiesel. For viscosity, this is compatible with Amita and Joshi (2014) who found that the biodiesel obtained from castor oil provided satisfactory values of density and saponification but its viscosity was very high and cannot be directly used in diesel engine.

Dilution, micro-emulsification, pyrolysis and blending are the four techniques applied to solve the problems encountered with the high fuel viscosity. For improving the biodiesel quality, it is recommended to blend the biodiesel obtained with other diesel to minimize the viscosity of fuel. Castor biodiesel can be used by blending with other methyl ester or mineral diesel up to 10 to 20\% (Amita and Joshi 2014). The viscosity further reduced by blending with diesel up to $30 \%$ to get within the Indian Standard Limit (Anand et al.2010).

\section{CONCLUSION}

It can be concluded from this study that marginal water as El-Salam water can be utilized for the production of non-edible plants for the production of biodiesel. Biofertilization and growth promoting hormones can be recommended to be applied for increasing productivity, plant uptake of nitrogen and phosphorus, trace and heavy metals in shoot and oil content of castor plants. While esterification of the castor oil can be suggested for the reduction of its viscosity and biodiesel production, further methods as blending with other diesel were recommended for improving the biodiesel quality.
A.O.A.C., 1990. Official Method of Analysis. $12^{\text {th }}$ Association Official Analytical Chemists, Washington, D.C. (U.S.A.).

Abdel-Rahman, M E and S. El-Demerdashe 2003 Assessment of certain micronutrients and pollutant elements in soils of Tushka. Egyptian J Desert Res., 53, 1: 81-99.

Adriano, D. C. 1986 Trace elements in the terrestrial environment. Springer-verlage. New York.

Agarwal, D. L. Kumar and A.K. Agarwal. 2008. Performance evaluation of a vegetable oil fuelled compression ignition engine; Renewable Energy. 33:1147-1156.

Alvarez, R., S. J. Nissen and E. G. Sutter.1989. Relation between indole-3-acetic acid levels in apple (Malus pumlla Mill) rootstocks cultivated in vitro and adentittious root formation in the presence of indole-3-butyric acid. Plant Physiol. 89:439-443.

Amin, A. A., E.S.M Rashad and F.A.E. Gharib.2006.Physiological Responses of Maize Plants (Zea mays L.) to Foliar Application of Morphactin CF125 and Indole-3-butyric Acid. Journal of Biological Science 6: 547-554.

Amita, N and S. Joshi. 2014. A Study on Castor Oil and Its Conversion into Biodiesel by Trans-esterification Method. Nepal J. of Sci. and Tech. 15(1): 45-52

Anand, K., R. Avishek and S. M.Pramod .2010. Estimating the Viscosity of Vegetable Oil and Biodiesel Fuels. India Energy Fuels. 24 (1). pp:664-672.

APHA (American Public Health Association) .1998.Standard Methods for the Examination of Water and Wastewater. 20th Edition, American Public Health Association, American Water Works Association and Water Environmental Federation, Washington DC.

Ashrafuzzaman, M., A.H.R.I.M. Farid, H.M.d. Anamul, I.S.M. Zahurul, S.M. Shahidullah and S. Meon.2009. Efficiency of plant growth-promoting rhizobacteria (PGPR) for the enhancement of rice growth. African J. of Biotech. 8 (7): 1247-1252

ASTM D6751 .2015.Standard Specification for Biodiesel Fuel Blend Stock (B100) for Middle DistillateFuels (ASTM International, West Conshohocken, PA) DOI: 10.1520/D6751-15CE01.

Ayers, R.S. and D.W. Wescot .1994. Water quality for agriculture, FAO Irrigation and Drainage Paper 29. Rome, Italy.

\section{REFERENCES}


Badawy, K. Reham. 2005. Bioremediation and Chemical Treatment of some Heavy Metals From Agroecosystem in some Polluted Soils. Ph. D., Thesis Faculty of Science, Al-Azhar University (Girls), Egypt.

Balba, A.M.1997. Soil and water resources and development in North Sinai, Egypt. Sahara Research and Review. 9:114.

Bashan, Y. and H. Levanony .1990. Current status of Azospirillum inoculation technology : Azospirillum as a challenge for agriculture. Canadian J. of Microbiol. 36: $591-608$.

Bedbabis, S., D.Trigui, C. Ahmed, M. L.Clodoveo, S.Camposeo, G. Vivaldi and B.Rouina. 2015. Long-terms effects of irrigation with treated municipal wastewater on soil, yield and olive oil quality. Agric. Water Manage. 160:14-21.

Caldwell, B.A. 2005. Enzyme activities as a component of soil biodiversity: a review. Pedobiologia 49, :637-644

Conceicao, M.M., R.A. Candeia, F.C. Silva, A.F. Bezerra, V. FernandesJr and A.G. Souza. 2007. Thermoanalytical characterization of castor oil biodiesel. Renewable and Sustainable Energy Reviews. 11(5): 964-975.

Demirbas, A., 2007. Biodiesel from sunflower oil in supercritical methanol with calcium oxide. Energy Conv. Manag. 48: 937-941.

Egamberdieva, D .2009. Alleviation of salt stress by plant growth regulators and IAA producing bacteria in wheat. Acta. Physiol. Plant, 31:861-864

El-Baha, A. M., H. A. Abou-Gazia, M. Z. Salem, N. H. Mohamed and P. A. Salaheldin. 2016. Initial Growth Response and Chemical Composition of Moringa oleifera Seedlings to Different Levels of NPK and Biofertilizer at Two Different Soil Types. Alex. Sci. Exch. J. 37:186-196.

El-Demerdashe S, and M. E. Abdel-Rahman. 1997. contamination of calcareous soil with nickel and cadmium. Egypt J. Appl. Sci. 12(10): 233-256.

Elmerich, C. 1984. Molecular biology and ecology of diazotrophs associated with non leguminous plants. BioTech. 2:967- 978.

EPA (Environment Protection Authority) .1991. Guidelines for wastewater irrigation. Publication 168, Environment Protection Authority, Melbourne.

Freed, R. D. 1991. MSTAT-C Directory crop. Soil Science Dept., Michigan Univ. USA.

Goma, B. S. 2007. Behaviour of some heavy metals as related to soil mineralogy in some Egyptian desert soils. M.Sc. Thesis, Faculty of Agriculture, Alexandria University, Egypt.

Hanifi S. and I. El Hadramy .2008. Phytotoxicity and fertilising potential of olive mill wastewaters for maize cultivation. J. of Agron. Sustain. Dev. 28: 313-319.
Hassan, F. A., L. I. El-Juhany, and M. S. Shehatah.2002. Effects of irrigation with sewage effluent on the growth of some forest tree species and physical and mechanical properties of the soil. In: the Proceedings of the Second Conference of Sustainable Agricultural Development. pp: 300-311.

Hesse, P. R. 1971. A textbook in soil chemical analysis. William Glowe, London .

Hu, X., Y.Jiang, Y.Shu, X.Hu, L.Liu and F.Luo.2014. Effects of mining wastewater discharges on heavy metal pollution and soil enzyme activity of the paddy fields. J. Geochem. Explor. 147: 139-150.

Ingle, S. S. and V. M. Nandedkar .2010. Castor oil biodiesel an alternative fuel for diesel in Compression Ignition Engine.IOSR J. Mech. and Civil Engineer. 0-13.

Jackson, M. L. 1963. Soil chemical analysis. Constable and Comp. Ltd., England.

Kabesh, M.O., T.A.Nour and M.S.M. Saber.1989. Utilization of biofertililizers in increasing field crop production 5Effect of some chemo-and/or bio-additives on growth and yield characteristics of soybean plants. Bull. of Egypt. Sco. Physiol. Sci. 9(4):13-24.

Khan, S., Q.Cao, Y.M. Zheng, Y.Z. Huang and Y.G. Zhu. 2008. Health risks of heavy metals in contaminated soils and food crops irrigated with wastewater in Beijing, China. Environ. Pollution. 152: 686- 692.

Lin, L. and X. Xu .2013. Indole-3-acetic acid production by endophytic Streptomyces sp. isolated from medicinal plants. Curr Microbiol. 67 (2):209-217.

Lindsay, W. L. and W. A. Norvell. 1978. Development of DTPA soil test for zinc, iron, manganese and copper. Soil Sci. Soc. Am. J. (42): 421-428.

MacDonald, H. 1997. Auxin perception and signal transduction. Physiol. Plant. 100: 423-430.

Nicholson, G. 1984. Methods of soil, plant and water analysis. N Z Forest Service. FRI Bulletin No. 70.

Nordstrom, A., J. F.Alvarado and L. Eliasson.1991. Effect of Exogenous Indole-3-Acetic Acid and Indole-3-Butyric Acid on Internal 45 Levels of the Respective Auxins and Their Conjugation with Aspartic Acid during Adventitious Root Formation in Pea Cuttings. Plant Physiol. 96(3):856861.

Norvell, W.A. 1984. Comparison of chelating agents as extractants for metals in diverse soil materials. Soil Sci. Am. J. 48:1285-1292.

Okullo, A., A.K Temu, P. Ogwok, and J.W Ntalikwa.2012.Physico-chemical properties of biodiesel from jatropha and castor oils, Int. J. of Renewable Energy Res. 2: 47-52.

Othman, A.A., S.A.Rabeh, M.Fayez, M.Monib and N.A. Hegazi. 2012. El-Salam canal is a potential project reusing the Nile Delta drainage water for Sinai desert agriculture: Microbial and chemical water quality. Journal of Advanced Research. 3 (2): 99-108. 
Panwar, N. L., Y. H. Shrirame, N. S. Rathore, S. Jindal and A. K. Kurchania. 2010. Performance Evaluation of a Diesel Engine Fueled with Methyl Ester of Castor Seed Oil,.Applied Thermal Engineering. 30(2) : 245-249.

Peach, K. and M.V. Tracey .1956. Modern method of plant analysis. Vol. 1. Berlin: Springer-Verlag. p. 4.

Pepper, I.L., C.P. Gerba and J.W. Brendecke.1995. Dehydrogenase activity of soils. In:Environmental Microbiology: A Laboratory Manual, Academic Press, New York.pp:51-56.

Piper, C. S. 1950. Soil and plant analysis. Inter science Inc.New York.

Qaiser, H., H.Shamsul, A.Barket and A.Aqil.2009. Auxin Analogues and Nitrogen Metabolism, Photosynthesis, and Yield of Chick pea. Journal of Plant Nutrition. 32.(200): 1469-1485.

Reeves, R. D. and A. J. M.Baker. 2000. Metal Accumulating. In: Raskin, I.B., Ensley, D. (Eds.), Phytoremediation of Toxic Metals: Using Plants to Clean Up the Environment. Wiley, New York. pp:193 - 229.

Richards, I. A. 1954. Diagnosis and improvement of saline and alkali soils. USDA, Washington, USA, Handbook No. 60.160 .

Rowell, DL. 1993. Soil science: methods and applications. New York: Department of Soil Science, University of Reading. Co-published in the US with John Wiley and Sons Inc.

Salisbury, F.B. and C.W. Ross.1992. Plant Physiology, Hormones and Plant Regulators: Auxins and Gibberellins. 4th Edition, Wadsworth Publishing, Belmont.pp:357-381.

Sharma, N. K. and K. S. Dadhwal. 1996. Prominent agroforestry practices in the Saharanpur plains of Uttar Pradesh - a case study, Indian J. of Soil Conservation. 24:172-173.

Simon, L. 1998. Cadmium accumulation and distribution in sunflower plant. J. Plant Nutr. 21: 341-352.
Smith, S.R 1994. Effect of soil pH on availability to crop of metals in sewage sludge treated soils. I. Nickel, copper and zinc uptake and toxicity to ryegrass. Environ. Pollut. 85: 321-327.

Sreenivas, P., V. R.Mamilla and K.C. Sekhar. 2011. Development of Biodiesel from Castor Oil International J. of Energy Sci. (1).3: 192-197.

Tan X., Y.Liu, K.Yan, Z.Wang, G.Lu, Y.He and W. He .2017. Differences in the response of soil dehydrogenase activity to $\mathrm{Cd}$ contamination are determined by the different substrates used for its determination. Chemosphere. 169:324-332.

Tanwar, S.P.S. and M.S. Shaktawat. 2003. Influence of phosphorus sources, levels and solubilizers on yield, quality and nutrient uptake of soybean - wheat cropping system in southern Rajasthan. Indian J. Agric. Sci.73(1): 3-7.

Tina, P.T.D., M.BirneybDick and L.Aulda. 2012. Viscosity reduction of castor oil esters by the addition of diesel, safflower oil esters and additives Volume 36, Issue 1, March. P: 267-270

Toze, S. 2005. Reuse of effluent water-benefits and risks Agric. Water Manag. 80 pp:147-159

WEF (Water Environment Federation). Using reclaimed water to augment potable water resources. Alexandria, VA, USA.1998.

White, C. , J. A.Sayer, and G. M.Gadd.1997. Microbial solubilization and immobilization of toxic metals: key biogeochemicxal processes for treatment of contamination. FEMS Microbiol. Rev. 20:503-516.

WHO, World Health Organization .2006. Guidelines for drinking-water quality, incorporating first addendum. Recommendations. 3rd ed. vol. 1. Geneva: World Health Organization. P: 515.

Yehia, H.M. and S.Z. Sabae. 2011.Microbial pollution of water in El-Salam Canal, Egypt. Ameri. Eur. J. Agric. \& Enviorn. Sci. 11 (2): 305- 309. 


\section{الملخص العربي}

\section{تأثير التسميد الحيوي على إنتاجية وجودة الوقود الحيوي لزيت نبات الخروع تحت ظروف الرى بمياه ترعة السلام}

رهام كامل إبر اهيم بدوى، أمل محمد عمر ، دعاء إبر اهيم عثمان

أوضحث النتائج زياده تركيز العناصر الثقيله و النادرة فى

سيقان النباتات التى تم معاملتها بإستخدام الرش الورقى أو

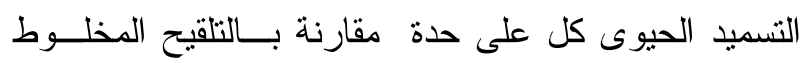
منهما. كما أدى إستخدام التـسميد الحيــوى ببكتيريـــا ال Azotobacter chrococcum حمض الخليك و إندول حمض البيوتاريك إلى أعلى زيـــادة معنوية لسماحية العناصر الثقيلة بمحلول التربه. كما أظهرت النتائج أن لزوجه عينات زيـــت الخـروع المقاسة عند درجه حراره مب درجه سيلزيه أعلـى مسـن لزوجه الديزل البترولى كما لا يوجد إختلاف ملحوظ فــى

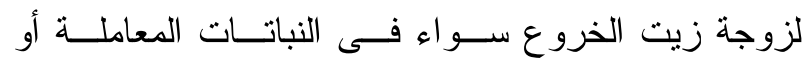

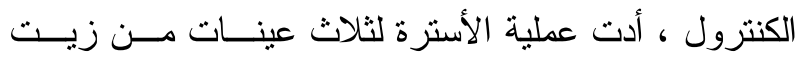
الخروع إلى إنخفاض للزوجتها مما مكن من إنتاج الــديزل الحيوى. أظهرث خو اص ثثلاث عينات البيوديزل مطابقــة flash and cloud point اللزوجة ، carbon residue and heat resistance أرتفاعا عن مع المدى القياسى للبيوديزل. لذلك يوصــى بخلـــ الــديزيل الحيوى المستخلص من زيت الخروع مع الديزل البترولـى لتقليص اللزوجة لإستخدامه كوقود. الكلمات الالالة: الأزوتوبكتر، البيوديزل ، نبات الخـروع ، مياه الرى لترعة السلام ، الرش الورقى ، البـسودومونس، العناصر الثقيلة.
تم إستغلال مياه ترعه السلام كمياه هامشيه فى زر اعه المحاصيل غير التقليديه مثل نبات الخروع بهــدف إنتـــاج الوقود الحيوى.وتهدف الدر اسه إلى زياده محــصول نبـــات

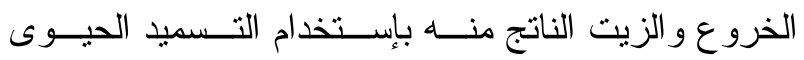
وهرمونات النمو النباتيه ـ تم إستخدام نوعين من السلالات البكتيريـــ Azotobacter chrococcum and Pseudomonas geniculata

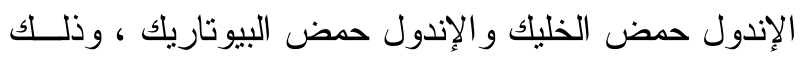
بالإضـافه الى الرش الورقى بالـهرمونــات النباتيـــه إنــدول حمض الخليك و إندول حمض البيوتاريك. تم إجراء تجربه حقليه في منطقه بالوظه بشمال سيناء، و التى يتم ريها بمياه نرعه السلام، وقد أفادت النتــائج أن التلقيح بإستخدام التسميد الحيوى أو بالرش الورقى لكلا من منفردين أو مجتمعين كان له تأثير أيجابياً (IBA \& IAA) على كل قياسات النمو لنبات الخروع بالإضافة إلى معــدل الإمتصاص للنيتروجين و الفوسفور بالإضافة لأعداد و النشاط الميكروبى بمنطقه الجذور • وقد سجل رش النباتات بحمض البيوتاريك مع التلقيح باستخدام بكتيريـــا ال Azotobacter Pseudomonas geniculata ثم تبعة التلقيح ب chrococcum أعلى النتائج من حيث طول النبات ووزن النورات و الوزن الجاف للنبات ووزن . . . ابذرة وكمية الزيت. 